\title{
Comunicar y traducir: una perspectiva científica para un enfoque didáctico
}

\section{Communicating and translating: a scientific perspective for a didactic approach}

\section{Simone Greco}

Università degli Studi di Bari Aldo Moro simone.greco@uniba.it

ORCID ID: http://orcid.org/0000-0002-2202-5810

DOI: $10.17398 / 1988-8430.34 .49$

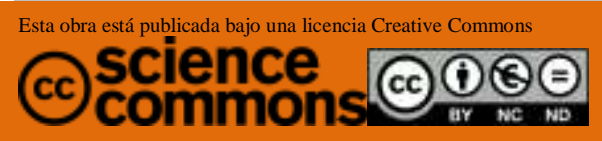

Fecha de recepción: 11/01/2021 Fecha de aceptación: 29/01/2021

OPEN $\because$ ACCESS

Greco, S. (2021). Comunicar y traducir: una perspectiva científica para un enfoque didáctico. Tejuelo, $34,49-82$.

Doi: https://doi.org/10.17398/1988-8430.34.49 
Resumen: Este artículo propone enfocar el tema de la comunicación y de la traducción desde una perspectiva científica y con un propósito didáctico, de acuerdo con la idea de la dinamicidad del lenguaje y de la noción de interculturalidad, en función de la tramitación del mensaje.

Palabras clave: traducción; didáctica; lenguas extranjeras; contrastes; afinidades.

\begin{abstract}
In this article, an attempt will be made to approach the subject of communication and translation from a scientific perspective and with a didactic purpose, in accordance with the idea of the dynamics of language and the notion of interculturality, depending on the processing of the message.
\end{abstract}

Keywords: translation; teaching; foreign languages; contrasts; similarities. 


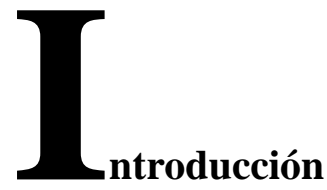

Partimos del supuesto de que el dinamismo y la versatilidad de los códigos lingüísticos inciden en la existencia de contrastes y analogías entre lenguas en contacto, ya que todas pueden "hacer cosas con sus palabras"

El lenguaje consiste en algo más que significados de signos y combinaciones de signos; es esencialmente un código dinámico o, dicho de otro modo, un código que funciona con uno o varios propósitos determinados. Así pues, tenemos que analizar la transmisión de un mensaje dentro de una dimensión dinámica (Nida, citado en Hurtado, 2001, p. 522).

A fin de establecer una comunicación exitosa, hay que enfocar paralelamente los dos códigos, aprovechar el bagaje cultural para progresar en el aprendizaje de la lengua extranjera (LE) y, después de

\footnotetext{
${ }^{5}$ Esta expresión está claramente inspirada en How to do things with words [Cómo hacer cosas con palabras] (Austin, 1962), cf. nota 3.
} 
discernir y coordinar el componente lingüístico con el sociolingüístico y el pragmático, detectar cualquier discrepancia o analogía que pueda sugerir cómo avanzar en la aproximación a la otra lengua y cultura. En el paso de una lengua a otra, en efecto, las competencias comunicativas del usuario se organizan en redes que dinamizan las conexiones nocionales y perfeccionan un saber que ha de coincidir con el dominio de la cultura.

El proceso de aprendizaje no debe prescindir de la apropiación de los diversos matices que el código lingüístico puede asumir, según el contexto, para que la actuación lingüística pueda llevarse a cabo, si bien desvinculada del automatismo expresivo de la lengua nativa. Es necesario aprender a transpensar, de acuerdo con la acepción que de este vocablo da su acuñador, José Martí: «Pensar a través de otro, estudiar su pensamiento, pensar como el otro» (citado en Pampín, 2012, p. 61). Interpretar, por lo tanto, el constituyente lingüístico del enunciado junto con el extralingüístico para que la comunicación logre su objetivo, esto es, comunicar.

Así pues, las redes interculturales agilizan el contacto entre las lenguas $\mathrm{y}$, mediante su dominio, el usuario puede conseguir una transmisión clara del significado previsto o, si actúa de mediador lingüístico, una continuidad informativa completa y funcional. Evidentemente, nos introducimos en una perspectiva de interculturalidad, lo que hace referencia a las numerosas y variadas facetas de la sociedad, cuya originalidad es necesario penetrar y asimilar para completar los conocimientos:

Cabe subrayar la pertinencia del término "interculturalidad", referido a una actitud que consiste en tomar conciencia de la variedad sin pretender homogeneizar las diferencias, frente a la palabra "multiculturalidad", que alude a un fenómeno de transición, con vistas a la fusión definitiva (Calvi, 2003, p. 107). 


\section{La comunicación intercultural y plurilingüe}

Aprender una lengua extranjera es establecer un nexo flexible y dinámico entre culturas y no solamente enfrentarse a las dificultades procedentes de la diferencia más o menos marcada entre los códigos lingüísticos. Recordemos que insistir en las diferencias puede determinar el estancamiento del aprendizaje o mermar el sentido de confianza en el nuevo idioma:

Aunque la gramática y el léxico sean herramientas esenciales en la comunicación, para la adquisición de una lengua no sólo hay que tener conocimientos lingüísticos sino ser capaz de actuar en la sociedad de la lengua meta (Founts, 2006, ap. 1.3.).

El aprendizaje del nuevo código debe incorporarse en un proceso que, traspasando lo estrictamente lingüístico, aborde detalladamente la otra cultura, incluyendo sus aspectos menos explícitos, como lo sobreentendido, las experiencias idiosincrásicas y las convicciones:

[Alcanzar la] "competencia comunicativa intercultural" no significa, por lo tanto, aprender un repertorio de fórmulas de comportamiento, intentando anular la propia identidad cultural, sino más bien desarrollar una "identidad plural", que procede de la combinación de aportaciones diferentes; las experiencias afectivas, además, deben conjugarse con el conocimiento explícito, cognitivo, de la cultura extranjera (Calvi, 2003, p. 113).

A ello hay que añadir también los aspectos sociolingüísticos y pragmáticos que caracterizan y determinan la realización comunicativa, en la que juega un papel fundamental el contexto, ya que puede determinar las secuencias de la interacción.

Así pues, debe abordarse el aprendizaje de lenguas según el ámbito cultural en el que estas han madurado; el sistema de valores y de creencias en el que viven las lenguas debe ser motivo de reflexión didáctica, para facilitar, mediante contextos auténticos, una lectura diacrónica de las informaciones y eliminar los clichés, dado que los 
estudiantes perciben de una manera diferente la cultura ajena, desde su propia perspectiva etnocéntrica:

La enseñanza de lenguas extranjeras no puede plantearse el objetivo de emular los conocimientos operativos, "invisibles", que comparten los hablantes nativos; precisamente porque estos conocimientos son difíciles de describir, el intento de clasificarlos lleva a generalizaciones que derivan peligrosamente hacia el tópico (Calvi, 2003, p. 112).

Teniendo en cuenta todo lo anterior, el objetivo de un progreso gradual en el aprendizaje, que vaya conformándose en las secuencias del sistema intermedio de la interlengua — no siempre en progresivo avance, pues pueden producirse regresiones-, estimula una constante labor mediadora entre la esfera cultural inicial y la del ámbito lingüístico en el que se está penetrando:

El enfoque intercultural sugiere que el alumno tome conciencia de los hábitos arraigados en el mundo al que se acerca y sus repercusiones lingüísticas, superando el reduccionismo de los tópicos; sin pretender sistematizar fenómenos muy variados, a veces diatópica o diastráticamente marcados, es oportuno que el alumno adquiera una competencia intercultural adecuada, que le permita desenvolverse en la realidad del país extranjero (Calvi, 2003, p. 112).

Ahora bien, esta actividad promueve la reflexión sobre la cultura ajena y la propia, puesto que la comunicación aprovecha cada aspecto común o punto de encuentro para evolucionar a través de la acción de los participantes:

Además de comprender la cultura meta, el alumno debe comprender la realidad de su propia cultura para que ésta no le impida la comprensión de la cultura extranjera (Founts, 2006, ap. 1.4).

Naturalmente, a fin de poder interactuar de manera adecuada, se ha de valorar en cada momento la comunicación, tanto desde el propio punto de vista como desde el ajeno, en una relación constantemente flexible con el copartícipe, que contemple todas las facetas de la interacción y no solamente la verbal: 
El plurilingüismo, además, tiene que contemplarse en el contexto del pluriculturalismo. La lengua no es sólo un aspecto importante de la cultura, sino un medio de acceso a las manifestaciones culturales. En la competencia cultural de una persona, las distintas culturas (nacional, regional, social) a las que ha accedido esa persona no coexisten simplemente una junto a otra. Se las compara activamente, se las contrasta e interactúan para producir una competencia pluricultural enriquecida e integrada, de las que la competencia plurilingüe es un componente (Arriba y Cantero, 2004, p. 11).

De ahí que los diferentes entornos de las lenguas, que van más allá de lo estrictamente lingüístico, tiendan a integrarse en redes dinámicas, las cuales orientan el análisis de los nuevos datos desde el prisma del acervo cultural:

La comprensión cultural es la clave para la efectiva adquisición de la lengua extranjera. Por lo tanto, es necesario que el profesor capacite a los alumnos a desenvolverse en situaciones interculturales y que propicie el desarrollo de las estrategias necesarias para asegurar una base común para la comunicación (Founts, 2006, ap. 1.5.).

Más concretamente, proporcionando un mayor abanico de posibilidades comunicativas para conseguir una competencia interculturalmente plurilingüe, las redes que relacionan los idiomas y su entorno resaltan el papel imprescindible de la mediación, ya en su acepción de situación de contacto entre interlocutores con conflictos interculturales, ya en la de compromiso que se negocia entre una identidad cultural y el sistema de la LE:

El par de lenguas implicado en el proceso de enseñanza / aprendizaje es un factor que no se puede infravalorar a la hora de determinar cómo reaccionan determinados colectivos de estudiantes ante un ítem lingüístico más o menos complejo (Trovato, 2018, p. 26).

La labor mediadora se revela como un soporte concreto de la comunicación y como un auténtico elemento coadyuvante en el aprendizaje. La misma, abordada desde una perspectiva que hace hincapié en la versatilidad lingüística del encuentro interactivo en una lengua diferente de la materna, es capaz de activar la realización de actos simultánea y concurrentemente inter- e intraculturales: 
En el caso de culturas muy lejanas, las barreras de incomprensión pueden ser totales; pero cuando la distancia es menor, hay que aprovechar las orientaciones compartidas y hacer hincapié en los rasgos diferenciadores, adoptando entonces un planteamiento contrastivo, útil también para tomar conciencia de las diversidades internas (por ejemplo, entre las distintas variedades de una lengua) (Calvi, 2003, p. 112).

Nexos y paralelismos extralingüísticos en la secuencia enunciativa hacen que los copartícipes planteen comparaciones, reconozcan afinidades y compensen funcionamientos divergentes, para conseguir interpretar adecuada y oportunamente los referentes culturales.

\section{Lengua y comunicación}

Comunicar en una LE requiere que el usuario supere las mismas dificultades presentes en todo tipo de comunicación, al establecer contacto un emisor (E) con un destinatario (D), a través de un código común, para enviar un mensaje en un contexto (Jakobson, citado en Osimo, 2011, p. 24).

Lo que cambia en las seis variables de la realización comunicativa propuestas por Jakobson es la posibilidad de interferencia o ruido semiótico ${ }^{6}$, es decir, cualquier motivo que impida la transmisión completa del mensaje — un déficit en la expresión o en la comprensión, un ruido que cubra o distorsione la voz, una hoja faltante o manchadao que determine la inadecuada recepción de las intenciones del emisor ${ }^{7}$

6 Bruno Osimo (2011, p. 41) presenta este concepto con el término residuo, identificándolo con lo que el enunciar resta al enunciado y que, si de verdad fuera necesario, la comunicación puede intentar recuperarlo a través de su manipulación.

${ }^{7}$ Es el enfoque del lenguaje como acción formulado por J. L. Austin (How to do things with words, 1962) y J. Searle (Speech acts. An essay in the philosophy of language, 1969). La comunicación no se produce mediante adherencias de palabras u oraciones; al expresarse, el hablante realiza un acto de habla, porque no solo dice, sino que también hace algo: este actúa para afirmar, preguntar, prometer, convencer, mandar, etc. El acto de habla es, por tanto, una unidad funcional de la comunicación, 
o la recepción de intenciones diferentes a las del emisor (Osimo, 2011, p. 25):

\section{Figura 1}

La comunicación y el concepto de interferencia de Shannon y Weaver

\section{CONTEXTO}

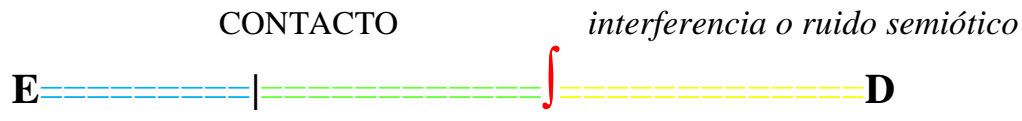

\section{MENSAJE}

Fuente: adaptado de Osimo, 2011, p. 24

Para no verse comprometida, de hecho, la comunicación debe poder contar con la activación inmediata de estrategias ${ }^{8}$ cuyo objetivo es atenuar la interferencia. Debe considerarse, además, que el uso de una LE - un código que los agentes pueden no dominar a la parsupone un escollo más en la realización verbal, ya que podría dar lugar a malentendidos o determinar la pérdida irrecuperable de una parte de la información.

Por tanto, comunicar en una LE requiere que, al establecer el contacto, los agentes sepan cómo obviar dificultades no solo lingüísticas, sino también culturales, y presten la debida atención a los

puesto que determina la dimensión interpersonal de cualquier enunciado y su intención.

${ }^{8}$ Estas estrategias giran en torno al cumplimiento de las funciones de la comunicación (Jakobson, citado en Osimo 2011, pp. 38 y ss.):

- función referencial, que provee a la contextualización del enunciado;

- función emotiva o expresiva, que suministra informaciones sobre el emisor;

- función metalingüística, que da informaciones sobre el código en uso y, evidentemente, va dirigida a la compensación de las diferencias intraculturales e interculturales de los agentes;

- función fática, que pretende minimizar la incidencia del residuo, para asegurar una comprensibilidad aceptable del mensaje;

- función conativa, que se proyecta sobre el destinatario, a fin de impulsar su reacción;

- función poética o estilística, relativa a la formulación del mensaje, a su forma. 
aspectos sociolingüísticos, los pragmáticos, lo sobreentendido, las convicciones, por mencionar los más significativos; en otras palabras, es necesario que los agentes sepan calibrar su realización comunicativa sobre la base de todas las implicaciones que esta conlleva:

Si el "cuerpo" de un idioma es su repertorio de voces, locuciones, estructuras y reglas combinatorias heredadas y empleadas por los hablantes, el "alma" es lo que estas formas revelan de la cultura acumulada de la sociedad en la cual se habla el idioma. Sin que nos demos cuenta de ello, en el desarrollo de nuestro idioma materno ha influido una serie de factores culturales (históricos, sociales, morales, etc.), algunos de los cuales son privativos del país o de la región donde vivimos. De un país a otro (o de una región a otra), estas influencias culturales pueden producir diferencias, tanto pequeñas como grandes, en todos los niveles del idioma (Steel, 1979, p. 1).

Es lo que Bruno Osimo (2011, pp. 35 y ss.) llama linguacultura, al explicar cómo una simple exclamación ${ }^{9}$ puede contener un sinfín de informaciones implícitas en un contexto que otra cultura podría no dar por sentadas o que la característica diamedial ${ }^{10}$ del texto puede $\operatorname{eclipsar}^{11}$ :

Questa differenza tra culture è la distanza che si interpone fra le stesse ed è esattamente il vuoto che un traduttore si propone di colmare al fine ultimo di rendere ogni cultura più accessibile all'altra. Si tratta di quel genere di fraintendimenti che si presenterebbero se un inglese e un giapponese cercassero di comunicare tra loro, ognuno parlando la propria lingua; ma paradossalmente lo stesso genere di equivoci può facilmente riscontrarsi all'interno della stessa lingua, o meglio, è un fenomeno che si verifica in continuazione ${ }^{12}$.

\footnotetext{
${ }^{9}$ Bruno Osimo presenta el ejemplo de la exclamación Ti pareva! (;Estaba claro!). ${ }^{10} \mathrm{El}$ adjetivo diamedial hace referencia a los fenómenos lingüísticos debidos a la forma escrita u oral.

${ }^{11}$ La elección prosódica, por ejemplo, es extremadamente reveladora de la intención comunicativa.

12 Traducción al español:

Esta diferencia entre culturas es la distancia que se establece entre las mismas y que coincide con el vacío que un traductor aspira a colmar, a fin de hacer cada cultura más accesible a la otra. Se trata de esos malentendidos que se producirían si un inglés y un japonés trataran de comunicar, cada cual en su idioma; paradójicamente el mismo tipo
} 
De esta manera, como ya había afirmado Agar (citado en Osimo, 2011, p. 36), al decir que «using a language involves all manner of background knowledge and local information in addition to grammar and vocabulary» ${ }^{13}$, el usuario se enfrenta a una constante labor de mediación — más bien cultural que lingüística, ya que la segunda forma parte de la primera-, en la que debe aprovechar sus competencias generales para acercarse al mundo de la LE y en la que cada punto de encuentro o cada dificultad afrontada y superada incrementan el porcentaje de éxito de la interacción:

Un aspecto importante de la FPC [formación por competencias] es la distinción entre competencias específicas (o disciplinarias), que son las propias de cada disciplina, y competencias generales (o transversales), que se aplican a todas las disciplinas. Se persigue, así, una formación de tipo holístico que integre ambas (Hurtado, 2019, p. $62)$.

Estas competencias generales (Marco Común Europeo de Referencia para las lenguas (MCER) 2002, pp. 99 y ss.) constan de una serie de subcompetencias que concurren en la maduración cultural del individuo: el conocimiento declarativo (saber) ${ }^{14}$ y el conocimiento sociocultural ${ }^{15}$. Junto a estos conocimientos, otros componentes son la

de equívocos puede darse en un mismo idioma, o mejor, es un fenómeno que ocurre muy a menudo.

${ }^{13}$ Traducción al español:

El uso de un idioma implica todo tipo de conocimiento y de información que sobre este se tiene, además de la gramática y el vocabulario.

${ }_{14} \mathrm{Al}$ conocimiento declarativo se adscribe el conocimiento del mundo, esto es, el conocimiento de saberes generales (geografía, física, concepto del tiempo, etc.) que se suponen en todo ser humano por su educación y pertenencia a una cultura y sociedad determinadas, así como por la experiencia y las fuentes de información de que dispone.

${ }^{15}$ El conocimiento sociocultural gravita en torno a la observación de la sociedad y de la cultura, con el que se reconocen los aspectos caleidoscópicos de la vida diaria, de las condiciones de vida, de las relaciones personales, de las creencias, del lenguaje corporal y de las convenciones sociales. 
consciencia intercultural $^{16}$ y las destrezas y las habilidades (saber hacer) prácticas (la capacidad de llevar a cabo acciones cotidianas y profesionales) e interculturales (la capacidad de empatía, entendida como una interrelación entre las diferentes culturas). Además, a estas competencias hay que añadir la competencia existencial (saber ser), conformada por la personalidad, las actitudes, las motivaciones, los valores y creencias del aprendiente, y también la capacidad de aprender (saber aprender), en la que se incluye la aptitud a la reflexión sobre la lengua, el uso de estrategias de aprendizaje y la facultad del individuo de saber observar, participando en nuevas experiencias, para incorporar nuevos conocimientos y enriquecer los propios.

Al dominio de estas competencias generales, debe unirse, ya en el estricto uso del lenguaje, el de la competencia comunicativa ${ }^{17}$, la cual también está integrada por varios componentes, centrados tanto en lo lingüístico como en la interrelación comunicativa entre agentes, por lo que se enfatiza en los elementos pragmáticos, estratégicos, sociolinguiísticos y discursivos que se yuxtaponen a los lingüísticos. Está claro que la comunicación depende de la armonía entre competencias que actúan interrelacionadas para conseguir un mensaje que cumpla su objetivo informativo y transmita significados y sentidos.

Dentro de la competencia comunicativa, la competencia lingüística ${ }^{18}$ coincide con la faceta más evidente de la interrelación, por intervenir en un nivel superficial y, por consiguiente, más inmediato, y afecta únicamente al dominio de los signos lingüísticos stricto sensu, es decir, de las unidades mínimas constituidas por un significante y un

\footnotetext{
${ }^{16}$ A través de la percepción, el conocimiento y la comprensión de las diferencias y similitudes entre la cultura propia y las ajenas, la consciencia intercultural se funda en la exploración de la diversidad para enriquecer el bagaje cultural.

${ }^{17}$ Para profundizar en este concepto, véanse Hymes (1971) y Canale y Swain (1980).

${ }_{18}$ Con sus seis subcompetencias, a saber: la competencia léxica, que remite al conocimiento y dominio del vocabulario; la competencia gramatical, que supone el conocimiento y el dominio necesarios para explotar los recursos gramaticales; la competencia semántica, que afecta al conocimiento y dominio del significado; la competencia fonológica, la competencia ortográfica y la competencia ortoépica, que se centran en la pronunciación y en la percepción de los elementos fónicos, atendiendo a su valor distintivo y funcional. (MCER, pp. 106 y ss.)
} 
significado, a su virtual intercambio en la dimensión paradigmática y a sus conexiones en el eje sintagmático.

Así pues, el MCER establece otras competencias junto a la lingüística, ya que esta no es suficiente para conseguir el dominio de una lengua, a saber, la competencia sociolingüística ${ }^{19}$ y la competencia pragmática ${ }^{20}$.

Evidentemente, la competencia lingüística se limita a proporcionar los instrumentos necesarios y las instrucciones esenciales para llevar a cabo la labor interactiva, pero, puesto que lengua y cultura se presentan como un todo indisociable, se deben atisbar las diferencias entre el bagaje cultural y las nociones recién adquiridas, apuntando a tejer redes interculturales. De ahí que resulte imprescindible el sondeo de los rasgos más relevantes de la nueva realidad, la insistencia en promover una reflexión profunda sobre las experiencias comunicativas y que esta reflexión ahonde en el análisis de efectividades y estereotipos, a fin de que, seleccionando indicios in itinere, se consolide el control de cómo usar el idioma.

\section{Actividades de la lengua: interacción y mediación}

El logro de la competencia global en LE va unido al desarrollo de las actividades de la lengua o destrezas comunicativas y, en el tema que nos ocupa, no puede prescindirse del desarrollo de las habilidades de interacción y mediación, tanto linguiística como cultural, durante todo el proceso de la interlengua.

Entre las diversas actividades de la lengua que tienen como objetivo la formación de un usuario de LE, el MCER y su volumen complementario (MCER ${ }^{b}, 2020$, pp. 70 y ss.) prevén también las de

\footnotetext{
${ }^{19}$ El dominio de los marcadores lingüísticos de relaciones sociales, las diferencias de registro, los dialectos y los acentos, refranes y dichos de sabiduría popular.

${ }^{20}$ La capacidad de realizar un uso comunicativo de la lengua en el que se tengan presentes las relaciones que se dan entre el sistema de la lengua, por un lado, y los interlocutores y el contexto de comunicación por otro, y que abarcaría varias otras competencias: la competencia discursiva, la funcional y la organizativa.
} 
interacción ${ }^{21}$ y de mediación textual ${ }^{22}$ y personal ${ }^{23}$, que completan las de expresión ${ }^{24}$ y comprensión ${ }^{25}$ y las contextualizan en ámbitos específicos (público, personal, educativo y profesional). La interacción, en cuanto acción que se ejerce recíprocamente entre dos o más agentes, se basa en la alternancia de actividades de expresión y comprensión, para promover y mantener un intercambio informativo sinérgico. Sin embargo, no es solo la resultante de estos dos procesos, dado que, en función del acto verbal —iniciativo o reactivo_-, debe activar múltiples estrategias comunicativas, hasta abarcar la quinésica y la proxémica. De hecho, según el Diccionario de términos clave de ELE (Martín Peris et al., 2008):

En contraposición a las actividades de expresión (por ejemplo, recitar un poema) o de comprensión (por ejemplo, leer un artículo académico), que comportan un proceso lingüístico unidireccional, en el que un usuario (hablante-escritor) produce un texto para expresar unas ideas, unos sentimientos, etc. y comunicarlos a unos destinatarios (lectores u oyentes), las actividades de interacción (por ejemplo, la conversación o la correspondencia) entrañan un proceso lingüístico bidireccional harto más complejo que la suma de un proceso de expresión más otro proceso de comprensión. En efecto, además de contener esos dos procesos, la interacción implica la construcción de un discurso conjunto y, por tanto, la creación colectiva de significado, elaborando más o menos el mensaje y explicitando más o menos el contenido, en función del grado de contexto mental común y experiencia compartida de los participantes.

${ }^{21}$ El usuario establece un diálogo «cara a cara» con un interlocutor. El texto del diálogo se compone de enunciados que se producen y se reciben por cada uno de ellos alternativamente.

${ }^{22}$ El usuario recibe un fragmento hablado o texto escrito en una lengua o código determinados, sin que el emisor esté presente, y produce un fragmento o texto paralelo en una lengua diferente (mediación interlinguiística) o en una variante del mismo código (mediación intralingüística), que será recibido a su vez por otro oyente o lector. ${ }^{23}$ El usuario participa como mediador en una interacción «cara a cara» de dos interlocutores que no comparten la misma lengua: recibe el texto en una lengua (L1 o LE) y lo convierte a la otra (LE o L1).

${ }^{24}$ El usuario o alumno produce un fragmento hablado o un texto escrito, que, a su vez, reciben con cierta distancia uno o más oyentes o lectores, de los que no se espera respuesta alguna.

${ }^{25}$ El usuario o alumno recibe, de nuevo con cierta distancia, un fragmento hablado o un texto escrito, que no precisa respuesta alguna. 
Ya sea hablada o escrita, la interacción supone múltiples operaciones cognitivas secuenciales, para evitar cualquier ruptura en la sucesión de actos lingüísticos ni en su coherencia.

La actividad de mediación, en cambio, podría considerarse una ampliación de la interacción y se produce cuando el usuario debe mediar, actuando de puente en el procesamiento o en la transmisión de un mensaje; es esencialmente interactiva, ya que interviene precisamente en las actividades de comprensión y de expresión:

La función del hablante como mediador abarca animar a otros a construir

significado, transmitir información, explicar cosas a otras personas cuando no las entienden, simplificar algo que es demasiado denso, resumir algo que es demasiado extenso y adaptar su lenguaje en el proceso. La mediación puede ser social, cultural, pedagógica, lingüística o profesional. Pero sea cual sea la forma que adopte, implica tender puentes para superar algún tipo de brecha o división. Por tanto, el mediador le resume o le parafrasea un texto a otro usuario de la lengua, que no comprende el mensaje debido a factores como el registro de lengua o la jerga del texto original (García, 2019, p. 209).

La mediación puede, por un lado, facilitar un mayor dominio del objeto de estudio, ya que favorece el análisis de una lengua (L1) — que puede ser la nativa o una que se domina - en función de la LE; por otro, resalta el papel imprescindible del experto en la LE en establecer un contacto entre agentes que no pueden interactuar:

Consideramos la Mediación como una actividad lingüístico-cultural dirigida a permitir que la comunicación fluya entre dos interlocutores que no comparten ni lengua ni cultura y al mediador como un facilitador de la comunicación, esto es, un puente entre las dos partes (Trovato, 2015, p. 71).

Esto hace que se tenga que vehicular no solamente el significado del enunciado en L1, sino también la intención perseguida por la secuencia de los actos de habla, con implicaciones discursivas, lingüísticas y estratégicas a nivel diafásico, diastrático y diatópico y según la caracterización diamedial: 
La lingua parlata, la lingua scritta - in contrapposizione alla lingua dei manuali di grammatica e dei dizionari - la lingua delle enunciazioni sono cariche di significati extradenotativi, locali, legati al contesto, al co-testo, alla cultura di cui sono prodotto, alle influenze, allo stile individuale e di sottoculture, alla connotazione, alle sfumature di senso, agli aspetti anche fonici del linguaggio. I problemi della marcatezza degli enunciati, del registro, dell'idioletto e del socioletto sono solo alcuni esempi dei nodi della scienza contemporanea della traduzione (Osimo, 2004, p. 30) ${ }^{26}$.

La recodificación en una nueva lengua, por ello, no puede ser automática, ya que solo el análisis atento del mensaje que se va a traducir podrá revelar implicaciones semánticas y referencias extralingüísticas ${ }^{27}$, dejando claro que habrá que apostar por un rediseño equivalente del contenido informativo y no de la forma expresiva.

A este respecto, Bruno Osimo (2011, pp. 63-64) retoma las ideas de Lotman para resaltar la diferencia entre buscar un rediseño equivalente del contenido y buscar la equivalencia total, lo que ambos consideran sumamente improbable, dado que, a diferencia del código matemático, la traducción, al operar con códigos no conmensurables, no puede sino producir diversidad:

Quando i due codici tra i quali avviene la traduzione sono uno discreto (quello verbale) e uno continuo (quello mentale), è impossibile alcun tipo di equivalenza. [...] Quando i due codici non sono

\footnotetext{
${ }^{26}$ Traducción al español:
}

La lengua hablada, la lengua escrita — en contraposición a la de los manuales de gramática y los diccionarios- y la lengua de las enunciaciones están cargadas de significados extradenotativos, locales, vinculados al contexto, al cotexto, a la cultura que las ha producido, a las influencias, al estilo individual y de subculturas, a la connotación, a los matices de sentido e incluso a los aspectos fónicos del lenguaje. Los problemas de la marcadez de los enunciados, los registros, el idiolecto y el sociolecto son solo algunos ejemplos de las dificultades de la ciencia contemporánea de la traducción.

27 Piénsese, por ejemplo, en la diferencia, aparentemente sutil, entre las dos colocaciones ocupar un edificio / okupar un edificio y en las implicaciones que comporta la simple sustitución de una letra. 
commensurabili, quello che si può fare è una metafora, più che un'equivalenza ${ }^{28}$.

La actividad de mediación se revela, pues, multifuncional y tiene como objetivo no interrumpir o desvirtuar el mensaje y contribuye a su comprensión correcta, evitando o tratando de aclarar los malentendidos que pueden minar el fin informativo. En definitiva, la mediación se configura como una nueva competencia, junto a la lingüística, la sociolingüística y la pragmática, y concurre a la solución de los conflictos comunicativos que pueden derivar de un malogrado intercambio de la información.

\section{Figura 2}

La competencia mediadora

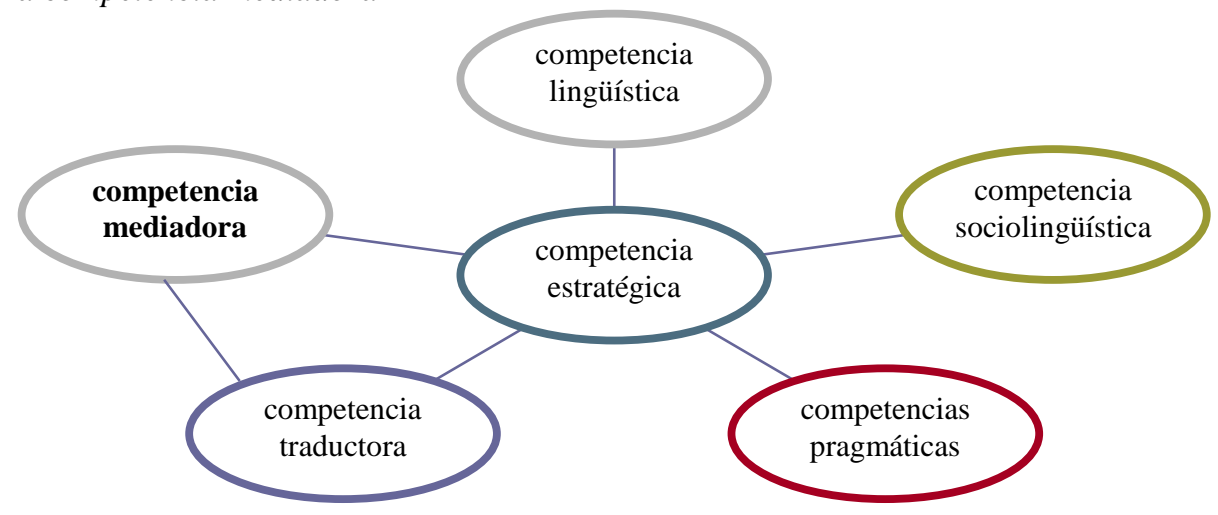

Fuente: adaptado de Arriba y Cantero, 2004, p. 19

\section{La actividad de mediación}

\subsection{Las subdestrezas de mediación}

La mediación lingüística es una de las actividades o destrezas que ya el MCER señala como coadyuvantes para el logro de la

\footnotetext{
${ }^{28}$ Traducción al español:

Cuando los dos códigos entre los cuales se realiza la traducción son uno discreto (el verbal) y otro continuo (el mental), es imposible algún tipo de equivalencia. [...] Cuando los dos códigos no son conmensurables, lo que se puede hacer es una metáfora más que una equivalencia.
} 
competencia comunicativa en LE y a la que el MCER b (pp. 90 y ss.) dedica gran importancia en una sección destacada. Esta actividad engloba varias subdestrezas ${ }^{29}$ que posibilitan al usuario para actuar de filtro y vínculo a la vez entre emisiones en códigos distintos o diferentes realizaciones en un mismo código, ya que interviene en la realización interactiva, en las actividades de comprensión y de expresión.

El mediador, por lo tanto, se configura como vehículo no solo del significado del enunciado en la lengua fuente, sino también, gestionando y tramitando la información, de la función planeada y de la intención perseguida por la secuencia de los actos de habla. Para que surta efecto, la labor mediadora, de hecho, debe saber controlar la elaboración de los actos comunicativos, extendiendo su dimensión no solamente a la traducción (mediación esencialmente escrita, aunque no solo: piénsese, por ejemplo, en los textos de mensajes grabados o de algún chat) y a la interpretación (mediación oral), sino también al resumen y a la paráfrasis y registrando significativas implicaciones discursivas, lingüísticas y estratégicas.

Tanto la mediación textual como la mediación personal reformulan los signos lingüísticos para conseguir una comunicación eficaz, por lo que actúan trasladando y conmutando el texto no solo entre lenguas, sino que deben tener en cuenta también la pluralidad de una misma lengua - en la que, a su vez, pueden aflorar diferencias de uso o registro y de usuario o dialecto-, para que la reconstitución del enunciado refleje el mensaje original en su verdadera dimensión.

Por todo lo anterior, es evidente que la recodificación debe ser el resultado de un análisis del texto que logre descifrar las implicaciones semánticas y revele las referencias extralingüísticas, dando por asumido que solo se puede obrar en el plano del contenido de la actuación comunicativa, ya que la equivalencia puntual en el de la expresión resulta una hipótesis errónea a priori.

${ }^{29}$ Subdestrezas de mediación textual: sintetizar, parafrasear, citar, traducir, apostillar y adecuar. Subdestrezas de mediación personal: resumir / sintetizar, parafrasear, apostillar, intermediar e interpretar (Cantero y Arriba 2004, p. 17). 
Debido a esta multifuncionalidad de la mediación lingüística, es necesario el desarrollo de una serie de subdestrezas, cuyo objetivo es posibilitar la reformulación de las secuencias de un texto en otras secuencias del mismo código o de otro, para una aprehensión más inmediata del significado original $\mathrm{y}$, de esta manera, hacer viable el contacto entre hablantes comunicativamente aislados. Para este estudio, investigaremos detalladamente la subdestreza de traducción.

\subsection{La subdestreza de traducción}

En la traducción, el papel del usuario es esencialmente interpretativo. Ya que su objetivo es reformular un texto fuente o prototexto (PT) en un texto meta o metatexto (MT), coincide con el fin y principio de dos realizaciones comunicativas (Osimo, 2011, p. 88):

\section{Autor - Texto $-\underline{\text { Receptor }=\text { Traductor }}-$ Texto - Receptor}

El traductor, por ello, juega un papel decisivo en la recepción del mensaje: debe entender el significado del original, gracias al análisis del enunciado, captar a su manera el sentido y trasladarlo todo a la otra lengua, poniendo en práctica sus competencias en la formulación de un texto que, sin embargo, solo podrá sugerir una vía de acceso al PT, es decir, la interpretación que el traductor elige y decide comunicar:

Ogni versione, a seconda del modo in cui il traduttore decide di farsi carico di ciò che non è possibile trasporre direttamente nella lingua 0 cultura ricevente, del "residuo intraducibile", mette in risalto alcuni aspetti e ne tace, ahimè, altri. In altre parole, ogni versione differisce dalle altre soprattutto per il contenuto (denotativo, ma soprattutto connotativo e stilistico) che il traduttore ha deciso di sacrificare in nome della comunicabilità, della "trasportabilità" del testo in questione (Osimo, 2011, p. 80) ${ }^{30}$.

\footnotetext{
${ }^{30}$ Traducción al español:
}

Cada versión, según la manera en la que el traductor decide hacerse cargo de lo que no es posible transponer directamente a la lengua o cultura receptoras, del "residuo intraducible", pone de relieve algunos aspectos e, infortunadamente, descarta otros. En otras palabras, cada versión difiere de las demás sobre todo en el contenido (denotativo, pero sobre todo connotativo y estilístico) que el traductor ha decidido 
Por todo lo anterior, ser experto en los códigos considerados no se corresponde exactamente con ser un buen traductor, ya que esta última habilidad sí depende de la otra, pero necesita más cualidades para aflorar:

Grammatica, lessico, punteggiatura, sono solo alcuni degli ostacoli che un traduttore si trova a dover affrontare al momento di tradurre da una lingua verso un'altra lingua. Consapevolmente o no, migliaia di altri fattori interferiscono e creano ostacoli che possono forse essere catalogati come culturali (Osimo, 2011, p. 36) ${ }^{31}$.

Saber llevar a cabo la labor traductora requiere el desarrollo de una preparación específica, la cual integra, evidentemente, la competencia comunicativa, puesto que estamos inclinados a pensar que la traducción, al transmitir informaciones, se centra en la comunicación. De hecho, la comparación de los códigos, que tiene como finalidad la elucidación de discrepancias y faltas de correspondencias interlingüísticas, solo puede ser una base sobre la que sustentar el estudio analítico de las culturas en juego:

La traducción obedece a los imperativos de la comunicación. No es una mera comparación y búsqueda de correspondencias, sino que es la búsqueda del sentido último de los mensajes. Así que la traducción requiere algo más que aptitudes lingüísticas (García-Medall, 2001, p. $1)$.

De esta manera, la traducción facilita la descripción de las circunstancias y de la razón de algunas realizaciones lingüísticas superficiales, las cuales, de otro modo, al resultar opacas e insondables, activarían un aprendizaje y un uso meramente mnemónicos.

sacrificar en nombre de la comunicabilidad, de la posibilidad de "transportar" el texto en cuestión.

${ }^{31}$ Traducción al español:

Gramática, léxico y puntuación son solo algunos de los obstáculos que un traductor tiene que afrontar al traducir de un idioma a otro. Evidentes o no, miles de otros factores interfieren y crean obstáculos que quizá podrían ser catalogados como culturales. 


\subsection{El procedimiento de la traducción}

La traducción prevé el reemplazo de los signos de una lengua fuente (LF) por los de una lengua meta (LM) -inicio y fin del proceso transformativo - y debe entenderse como el resultado de una praxis metodológica. La función de tal praxis encaja con el motivo de su ejecución: puesto que, desafortunadamente, los signos no son monosémicos sino polisémicos, de hecho, estos pueden comportar una significación múltiple y adquirir un significado temporal, que se cristaliza en una situación comunicativa dada.

La sustitución LF $\rightarrow$ LM, por consiguiente, requiere que se lleven a cabo algunas operaciones hermenéuticas y de reelaboración del mensaje, para que el enunciado llegue a recibirse, y que la comunicación entre emisor y destinatario, incluso con un contacto sui géneris, no se interrumpa.

Intentemos ahora glosar estas operaciones, siguiendo a Bruno Osimo $(2004$, p. I), quien las condensa en dos fases dinámicas, a las que añade una pasiva ${ }^{32}$ de crítica de la traducción; la lectura y el análisis del PT forman parte de la primera, mientras que la segunda consiste en la formulación del MT:

La prima contempla la lettura dell'originale e l'analisi del prototesto stesso in vista della sua traduzione. L'analisi traduttologia del prototesto ha lo scopo di individuare la dominante del prototesto e le possibili dominanti del metatesto, ossia quali aspetti sono più facilmente traducibili nella cultura ricevente e quali sono più importanti da tradurre nella cultura ricevente. In questa fase è anche necessario individuare il residuo traduttivo ed escogitare una strategia per una resa di tale residuo al di fuori del testo tradotto: una resa meta testuale. [...] La seconda fase consiste nella stesura vera e propria del testo tradotto, cioè del metatesto ${ }^{33}$.

${ }^{32}$ Fases dinámicas y fase pasiva, según el traductor actúe en mayor o menor medida. Se ha optado por el adjetivo dinámica en lugar de activa, para subrayar la función mediadora del traductor.

33 Traducción al español:

La primera contempla la lectura del original y el análisis del prototexto con vistas a su traducción. El análisis traductológico del prototexto tiene como objeto reconocer la 
Es el uso, decíamos al principio de este apartado, lo que le atribuye significado al significante y el significado cristaliza en una situación específica, por lo que este depende del cotexto, es decir, de la relación con las demás unidades semánticas, y del contexto, esto es, de la referencia extralingüística. Adicionalmente, no hay que olvidar que los signos que componen el mensaje - tanto en la LF como en la LMson el resultado de la codificación de pensamientos de emisores diferentes (Osimo, 2011, p. 25), tal vez lejanos en el espacio y en el tiempo, cada uno con su formación, su experiencia, su forma de ser y su perspectiva en la visión del mundo:

La traduzione di un testo presenta alcune analogie con la percezione visiva di un oggetto con un occhio solo, e come questa è lungi dall'essere perfetta. Non è mai possibile stabilire con certezza se una data interpretazione di un testo sia o no legittima, a meno che in soccorso del traduttore venga l'autore, unica autorità indiscutibile (Osimo, 2011, p. 82) $)^{34}$.

La traducción no implica la simple transferencia formal de expresiones; antes bien, ha de identificarse sobre todo como el traslado del núcleo semántico del texto, según una nueva forma y nuevos vocablos $\mathrm{y}$, en definitiva, una nueva estructura verbal:

La noción de equivalencia tiene una relación directa con la transposición del significado en las dos lenguas. Son especialmente importantes los aspectos semántico, pragmático y textual del significado. El semántico no necesita mayor explicación; el pragmático se refiere al estudio de los objetivos del uso de oraciones

función dominante del prototexto y las posibles funciones dominantes del metatexto, es decir, qué aspectos resultan más fáciles de traducir y cuáles es más importante transmitir a la cultura receptora. Asimismo, en esta fase resulta necesario determinar el residuo de la traducción y delinear una estrategia para proponer este residuo fuera del texto traducido: una reformulación metatextual [...]. La segunda fase consiste en la verdadera redacción del texto traducido, es decir, el metatexto.

${ }^{34}$ Traducción al español:

La traducción de un texto presenta algunas analogías con la percepción visual de un objeto con un ojo solo y cómo esta dista de ser perfecta. Es imposible establecer con certeza si una interpretación de un texto es legítima, a menos que el autor, única autoridad indiscutible, venga en auxilio del traductor. 
como unidad de habla; el textual se refiere a los aspectos cohesivos de un texto (Calvo, 2007, p. 2).

En este orden de ideas, la traducción no ha de centrarse en el significado objetivo de las palabras en la LF. Dado que la lengua no es un simple sistema de signos con estructuras abstractas y reglas de combinación, sino que implica un conjunto de connotaciones, humor, figuras estilísticas, significados indirectos, frases irónicas y referencias culturales y sociales, la aprehensión del aspecto subjetivo del enunciado es una tarea clave, que, evidentemente, supone lecturas atentas y análisis textuales:

Appare evidente che una proporzione molto cospicua del messaggio completo è costituita da ciò che è dato per scontato, da ciò che è considerato implicito. Ma ciò che è implicito in un contesto culturale non coincide mai con ciò che è considerato implicito in un altro contesto culturale. Il traduttore ha sempre bisogno di tenere conto di questo aspetto. Il suo compito consiste nella mediazione culturale (di cui quella linguistica è solo uno dei tanti aspetti) tra la cultura emittente e quella ricevente. È necessario che il traduttore capisca qual è il contenuto globale di un testo, ossia qual è il contenuto esplicito e quale quello implicito (Osimo, 2011, p. 35) ${ }^{35}$.

La interpretación del sentido de un texto, en efecto, no es simple en absoluto y, por consiguiente, tampoco lo es lograr la equivalencia semántica entre el PT y el MT, puesto que las posibilidades de interferencias y deslices son múltiples:

Nel caso della traduzione, il fenomeno della mistranslation non è legato necessariamente a un desiderio inconscio, quanto a un'impotenza di cui siamo del tutto consapevoli: è impossibile capire tutto ciò che un autore vuole trasmettere con il suo testo, ed è

\footnotetext{
${ }^{35}$ Traducción al español:

Resulta evidente que una proporción muy conspicua del mensaje completo está constituida por aquello que se da por sentado, por lo que se considera implícito. Sin embargo, lo que es implícito en un contexto cultural no coincide nunca con lo que se considera implícito en otro contexto cultural. El traductor siempre necesita tener en cuenta este aspecto. Su tarea consiste en la mediación cultural (de la que la lingüística solo es uno de sus numerosos aspectos) entre la cultura emisora y la receptora. Es necesario que el traductor entienda cuál es el contenido global de un texto, es decir, cuál es el contenido explícito y cuál es el implícito.
} 
impossibile trasporre tutto ciò che si è capito in altra lingua, lasciando al lettore le stesse possibilità di comprensione/incomprensione e interpretazione presenti nell'originale. Si ha comunque un residuo. L'importante è tenerne conto (Osimo, 2011, p. 83) ${ }^{36}$.

Así pues, intentar establecer un nexo intercultural es decisivo; el usuario traductor debe determinar una macrofunción del original, sobre la base de sus constituyentes y microfunciones, y transferirla, junto con sus determinantes, a un sistema receptor:

Conoscendo le differenze esistenti tra le due culture (e tra i loro rispettivi valori impliciti) [il traduttore] potrà mediare in modo tale da considerare quale possa essere il residuo comunicativo di una traduzione meramente linguistica e di conseguenza attuare una strategia traduttiva complessiva che tenga conto di tale residuo e dei modi per convogliarlo (eventualmente al di fuori del testo vero e proprio) al lettore della cultura ricevente (Osimo, 2011, p. 35) ${ }^{37}$.

Esta transformación requerirá necesariamente que se determinen algunos ajustes y se activen algunas estrategias para compensar la incidencia de las pérdidas informativas en la comunicación y hacer que la nueva clave de lectura refleje la original o, mejor dicho, que la traicione lo menos posible:

En vez de forzar la estructura formal de una lengua con elementos ajenos a la misma, el buen traductor está dispuesto a hacer todos los cambios formales que sean necesarios para reproducir el mensaje de

${ }^{36}$ Traducción al español:

En el caso de la traducción, el fenómeno de la mistranslation no depende necesariamente de un deseo instintivo, sino de una incapacidad de la que somos conscientes: es imposible entender todo lo que un autor quiere trasmitir con su texto y es imposible transponer todo lo que se ha entendido a otra lengua, dando al lector las mismas posibilidades de comprensión/incomprensión e interpretación presentes en el original. Se tiene, de todas formas, un residuo. Lo importante es tenerlo en cuenta.

${ }^{37}$ Traducción al español:

Conociendo las diferencias entre las dos culturas (y entre sus valores implícitos), [el traductor] podrá mediar para considerar cuál puede ser el residuo de una traducción meramente lingüística y, por consiguiente, aplicar una estrategia traductiva global que tenga en cuenta tal residuo y los modos para transmitirlo (eventualmente fuera del auténtico texto) al lector de la cultura receptora. 
acuerdo con las normas estructurales propias de la lengua receptora (Nida y Taber, 1986, p. 19).

Esto, según las cuatro condiciones que Bruno Osimo (2011, pp. 15-16) señala como indispensables en el procedimiento de recodificación:

- que una parte del texto se mantenga intacta,

- que una parte se modifique,

- que otra, por ser intraducible, no se traduzca (residuo),

- que en una parte se añadan informaciones.

Estas condiciones deberían ayudar a mantener el control de la transmisión global del mensaje y a monitorizar que se defina ex novo la eficacia textual y que esta cuadre con la finalidad informativa. Se deduce que el conocimiento del léxico, de la gramática y de los usos de la LF y de la LM, así como estar constantemente al día con los nuevos giros y términos, resultan facultades imprescindibles para la matización de las variedades diafásicas, diastráticas, diamésicas y diatópicas de las lenguas y para reducir las pérdidas más o menos sensibles en la comunicación.

De esta manera, la competencia textual le brinda al usuario de una lengua la posibilidad de penetrar en los textos, detectar e interpretar los aspectos discursivos y saber distinguir entre una pluralidad de realizaciones lingüísticas, lo que indudablemente redunda en beneficio de la mediación.

El usuario de la LE, de hecho, capacitado para comprender y producir enunciados lógicos, coherentes y cohesionados en L1, trata de aprovechar estas destrezas, con la finalidad de proyectar las características textuales del original al MT, desarrollando tanto el aspecto universal de su competencia como el específico e inherente a las lenguas en contacto. El usuario descodifica y reelabora un PT, leyéndolo o escuchándolo e interpretándolo, para reescribirlo en un código distinto o en otras secuencias del código original, tras atender a operaciones cognitivas que promueven el estudio analítico de los signos originales a nivel léxico, semántico, sintáctico y pragmático. Debe 
también profundizar en el detalle de la secuencia comunicativa, accediendo a su acervo cultural y lingüístico, para elegir cómo reconstruir verbalmente el concepto, según el contexto y el cotexto:

Il traduttore è quindi il linguista che analizza i dati sulla base di una concezione del segno linguistico che tiene conto di tutte le istruzioni che portano alla costituzione del testo e rivela l'insieme delle intenzioni comunicative, la tessitura intenzionale. Effettuerà in modo adeguato l'analisi del macrosegno (testo) se terrà conto delle quattro variabili che lo integrano: 1) il segno inteso come elemento singolarizzato (usato secondo le regole e le strategie imposte dai parlanti); 2) la struttura, che mette in evidenza le sue solidarietà sintagmatiche e paradigmatiche. Ricorrendo a un apparato concettuale e descrittivo che presuppone il perfetto possesso dei codici a confronto e degli universi di riferimento culturali sincronici e diacronici, collegherà il fatto linguistico (segno) alla 3) personalità (insieme delle condizioni psicosociologiche della produzione) e alla 4) cultura (le condizioni storiche che giustificano l'uso del segno tanto in diacronia quanto in sincronia) (Gambini, 2004, UD 4.6) ${ }^{38}$.

El reemplazo automático de los signos de la LF por los virtualmente correspondientes en la LM, de hecho, viciaría el contenido del original, llegando a resultar una mera recopilación de palabras en el sistema receptor, del cual solo lograría activar el aspecto verbal: palabras de la LM pero no expresadas en la LM, es decir, sin respetar su red, su sistema de configuración de sentido.

${ }^{38}$ Traducción al español:

El traductor es, pues, el lingüista que analiza los datos según una concepción del signo lingüístico, que considera todas las instrucciones que convergen en la constitución del texto y revela el conjunto de las intenciones comunicativas, la textura intencional. Elaborará de una manera adecuada el análisis del macrosigno (texto) si tiene en cuenta las cuatro variables que lo integran: 1) el signo per se (usado según las reglas y estrategias impuestas por los hablantes); 2) la estructura, que pone de relieve sus solidaridades sintagmáticas y paradigmáticas. Gracias a un aparato conceptual y descriptivo que presupone el perfecto dominio de los códigos en comparación y de los universos culturales de referencia sincrónicos y diacrónicos, relacionará el hecho lingüístico (signo) con la 3) personalidad (conjunto de las condiciones psicosociológicas de la producción) y con la 4) cultura (las condiciones históricas que justifican el uso del signo tanto en diacronía como en sincronía. 
En este orden de ideas, el análisis contrastivo resulta esencial para informar sobre el contorno de los vocablos. El cotexto habitual de los términos, en efecto, puede no coincidir en las diversas lenguas, por lo que es necesario subrayar el contraste entre los vocabularios en cuestión, la forma y la distribución de las palabras en una lengua y en la otra y la estrecha relación entre significado y sentido.

El análisis contrastivo brinda la oportunidad de aprender a conocer pari passu tanto la LM como la LF, ya que promueve la detección de diferencias imperceptibles y el control de semejanzas evidentes, y facilita, por consiguiente, la elección de sintagmas congruentes y semánticamente equivalentes.

Puesto que es natural, de hecho, que lenguas diferentes expresen de maneras diversas la misma significación — se habla de anisomorfismo de las lenguas-, la mediación debe perseguir una equivalencia funcional de los textos, según la cual estos se correspondan en lo que expresan y no en cómo lo expresan; esto, evidentemente, en una relación no siempre proporcional de los signos lingüísticos, la cual determina que, durante la reformulación, un signo linguiístico del PT pueda seleccionar más de uno en el MT o viceversa.

\subsection{La direccionalidad de la traducción}

\subsubsection{La traducción a la LE o inversa}

En este tipo de actividad, que responde más bien a las expectativas de los cursos académicos —en Italia, por ejemplo, la cátedra no es de lengua extranjera, sino de lengua extranjera y traducción-y que raras veces entra en los quehaceres profesionales, el usuario traductor vierte a la LE un texto que ha recibido en L1 - que sería de esperar que fuera la materna, pero que también puede ser una que este domina-, por lo que el producto debería codificarse sobre la base de una comprensión profunda del mensaje y dejar patente su función comunicativa. 
La aprehensión del sentido del original, de hecho, debería simplificar su reformulación en el MT: el conocimiento de qué expresar del PT orienta el cómo expresarlo en la LE e impulsa la activación de múltiples estrategias, tales como la solución del significado de períodos oscuros o la modulación o paráfrasis (la traducción de una palabra por una frase explicativa, con el objetivo de evitar tropezar con las posibles lagunas léxicas, gramaticales, sintácticas, etc.):

La traducción inversa es una actividad humilde y reveladora, que no tiene el prestigio de la competencia oral, pero es esencial para observar las idiosincrasias de la L2 y para mejorar en su competencia (García-Medall, 2001, p. 2).

Sin embargo, ya que la LM es la que menos se domina, aun la mínima falta de recursos en el repertorio plurilingüe puede estorbar la reformulación del contenido informativo, así que el usuario debe intentar subsanar sus carencias específicas tanto en la habilidad mediadora como, en general, en la competencia comunicativa; debería hacer hincapié en la abstracción de las unidades de traducción (texto, sección, párrafo, oración y unidades sintagmáticas léxicas) con el objetivo de comprobar cohesión y coherencia y debería insistir, sobre todo, en la exploración de las posibles equivalencias funcionales, mediante la consulta de diccionarios combinatorios y monolingües.

La traducción literal per se no puede llevar a un producto exitoso, dado que el paso puntual del código de origen al código meta debe respetar los vínculos léxicos propios del vocabulario de las lenguas y de sus posibilidades combinatorias.

En efecto, al traducir de la L1 a la LE, es plenamente posible si no esperable - la influencia interlingüística entre los dos códigos en contacto, porque la menor competencia en la LM puede activar un automatismo cognitivo que oriente hacia la transposición literal de las unidades léxicas del PT; sin considerar el contorno de las palabras, ni su plurisignificación intrínseca, se buscan improbables y virtuales equivalencias unívocas entre los vocablos, sobre todo si los idiomas son afines, debido a la superposición de signos: 
Hay que aceptar que no hay modo de esquivar la interferencia de la L1 a la hora de expresarnos en otro idioma (interferencia o transferencia negativa). Es más, tales interferencias demuestran que la conciencia lingüística sobre la L1 no puede ni debe eliminarse de un plumazo (García-Medall, 2001, p. 1).

\subsubsection{La traducción a la L1 o directa}

La realización de este tipo de actividad tiene como eje central la correcta comprensión del mensaje de partida en la LE, oral o escrito, para su reformulación en la L1:

La traducción directa exige precisión, uso adecuado de la gramática, conocimientos de fraseología y de estilo [...]. Lleva de modo natural al contraste de las lenguas en su uso (García-Medall, 2001, p. 2).

Entrando en detalles, mientras que el paso de la lengua oral a la escrita - la escucha de un texto en LE, por ejemplo, y su recepción y traducción consecutiva o simultánea a la L1 - se corresponde con la capacidad de comprensión y la de pasar, de forma más o menos inmediata, de una lengua a otra, operar con la lengua escrita brinda la oportunidad de llevar a cabo la traducción en lapsos sucesivos.

La lectura del PT debería facilitar, si no una interpretación profunda del enunciado, por lo menos, una comprensión global del mensaje, por lo que el producto debería reflejar una reformulación lo más fiel posible del mensaje original, si bien

Le traducteur vit en effet très souvent des moments de doute où il ne parvient plus à trouver «ce qu'il dirait dans sa langue pour dire la même chose que la personne qu'il traduit » (Farina, 2006, p. 151) ${ }^{39}$.

Así que, en ambos casos, el proceso cognitivo propenderá a impulsar la elaboración de un doble ejercicio traductor inter- e intralingüístico, de la LE a la L1 y de la L1 a la LE, para penetrar el

\footnotetext{
${ }^{39}$ Traducción al español:

El traductor, de hecho, vive a menudo momentos de duda en que no logra encontrar «qué diría en su lengua para expresar lo mismo que la persona a la que traduce».
} 
contenido semántico y el contexto sociocultural del PT e ir perfeccionando la codificación según el cotexto.

En comparación con la traducción inversa, la traducción directa simplifica la fase de reformulación, ya que la LM es la L1, que el usuario traductor debería necesariamente saber usar. Sin embargo, los conocimientos de la LE resultan fundamentales para la interpretación del PT, por lo que la carencia de nociones lingüísticas y extralingüísticas puede estorbar la descodificación y ralentizar, o incluso frustrar, la sucesiva codificación. Además, no se puede optar por aclarar el significado de los períodos poco transparentes, como en la actividad de traducción de la L1 a la LE, dado que su ininteligibilidad impide todo intento de simplificación.

Esto último revela que, de todos modos, la verificación del buen funcionamiento del texto producido ha de ser objeto de la actividad de traducción, ya que solo la comprobación de las correspondencias con el PT no garantiza la elaboración de una codificación funcional, en la situación comunicativa dada, dentro del mundo de la cultura receptora.

\section{Conclusiones}

Con el presente estudio, se ha intentado trazar una línea de investigación que articulara comunicación y traducción, haciendo hincapié en algunos aspectos del proceso didáctico. Se ha subrayado cómo comunicar es el resultado de varias competencias que han de activarse e interactuar para que el acto comunicacional logre su fin comunicativo, tanto en la lengua materna como en una lengua extranjera. En segundo lugar, se ha propuesto una perspectiva sobre la incidencia de dichas competencias en la subdestreza de traducción que, evidentemente, es otro aspecto de la comunicación.

Se ha demostrado que la comunicación $y$, por ende, la traducción, dependen de intricadas redes de saberes que las posibilitan, a pesar de las interferencias o las pérdidas que pueden intervenir en el flujo del mensaje. En la comunicación, una falta informativa - debida a un ruido o a un desgaste del texto, por ejemplo - puede subsanarse 
mediante las competencias del interlocutor; en la traducción, una pérdida de información —-debida, esta vez, a su intraducibilidadpuede ser compensada por medio de un añadido o de las competencias del destinatario.

En definitiva, sin ánimo de repetir un cliché, sigue siendo válido que todo resulta ser cuestión de competencia y, por tanto, abogamos por una configuración optimista que, sin embargo, no puede prescindir de una sólida preparación cultural afianzada y enriquecida por los resultados de la investigación didáctica:

La investigación didáctica supone la mejor aplicación y la mejor transferencia a la sociedad de la investigación traductológica, ya que garantiza una mejor formación de los futuros traductores, de modo que puedan ejercer la profesión atendiendo a las demandas e innovaciones sociales y alcanzando niveles de excelencia (Hurtado, 2019, p. 69).

Debemos, pues, seguir investigando sin cambiar de rumbo.

\section{Referencias bibliográficas}

Arriba García, C. D., y Cantero Serena, F. J. (2004). La mediación lingüística en la enseñanza de lenguas. Didáctica (Lengua y Literatura), 16, 9-21. Recuperado de http://revistas.ucm.es/index.php/DIDA/article/view/DIDA0404110009.

Calvi, M. V. (2003). El componente cultural en la enseñanza del español para fines específicos. En VV. AA., Actas del II Congreso internacional de español para fines específicos (pp. 107-122). Madrid: Ministerio de Educación y Ciencia.

Calvo Montaña, A. M. (2007). La evaluación de la calidad de la traducción: análisis y crítica del modelo de Juliane House. Anglogermanica online, 5, 2-15. Recuperado de https://roderic.uv.es/handle/10550/67585

Canale, M., y Swain, M. (1980). Theoretical Bases of Communicative Approaches to Second Language Teaching and Testing. Applied Linguistics, 1, 1-47. Versión en español: Fundamentos teóricos de los enfoques comunicativos, Signos, 17, (56-61) 18 (78- 
91). Recuperado de http://www.quadernsdigitals.net/datos/hemeroteca /r_3/nr_46/a_673/673.html.

Consejo de Europa (2002). Marco común europeo de referencia para las lenguas: aprendizaje, enseñanza, evaluación. Madrid: Anaya.

Consejo de Europa (2020). Common european framework of reference for languages: learning, teaching, assessment. Companion volume. Recuperado de https://rm.coe.int/common-europeanframework-of-reference-for-languages-learning-teaching/16809ea0d4.

Farina A. (2006). Traduction de syntagme: une utilisation dynamique des ressources lexicales sur support électronique. En F. San Vicente (Ed.), Lessicografia bilingue e traduzione: metodi, strumenti, approcci attuali. Milano: Polimetrica.

Founts, J. (2006). La enseñanza de la cultura en el aula ELE a través de la lectura: El cuento como revelador de la diversidad cultural del mundo hispanohablante. RedELE, Biblioteca, 5. Recuperado de http://www.educacionyfp.gob.es/mc/redele/bibliotecavirtual/numerosanteriores/2006/memoriamaster/1-semestre/founts.html.

Gambini, D. (2004). La traduzione nella prospettiva dell'insegnamento dell'italiano. ICON. Roma: Ministero dell'Istruzione, dell'Università e della Ricerca.

García Benito, A. B. (2019). Vuelta a escena de la traducción en la enseñanza de lenguas extranjeras: experiencia en PLE. Hermēneus: Revista de Traducción e Interpretación, 21, 197-234. doi: https://doi.org/10.24197/her.21.2019.197-234.

García-Medall, J. (2001). La traducción en la enseñanza de lenguas. Hermeneus: Revista de Traducción e Interpretación, 3, 113140. Recuperado de https://recyt.fecyt.es/index.php/HS/article/view/ $\underline{6083}$.

Hymes, D. H. (1971). Acerca de la competencia comunicativa. En M. Llobera Cànaves (Coord.) (1995), Competencia comunicativa. Documentos básicos en la enseñanza de lenguas extranjeras (pp. 2747). Madrid: Edelsa.

Hurtado, A. (2001). Traducción y Traductología. Madrid: Cátedra.

Hurtado, A. (2019). La investigación en didáctica de la traducción. Evolución, enfoques y perspectivas. En M. Tolosa Igualada 
y A. Echeverri (Eds.), Porque algo tiene que cambiar. La formación de traductores e intérpretes: Presente \& futuro / Because something should change: Present \& Future Training of Translators and Interpreters. MonTI, 11, 47-76. doi: https://doi.org/10.6035/ MonTI.2019.11.2.

Martín Peris, E. et al. (2008). Diccionario de términos clave de ELE. Recuperado de https:/cvc.cervantes.es/ensenanza/ biblioteca_ele/diccio_ele/diccionario/activestrateginteraccion.htm.

Nida, E. A., y Taber, C. R. (1974). The theory and practice of translation. Trad. Esp. (1986) La traducción: teoría y práctica. Madrid: Ediciones Cristiandad.

Osimo, B. (2004). Traduzione e qualità. La valutazione in ambito accademico e professionale. Milano: Hoepli.

Osimo, B. (2011). Manuale del traduttore. Milano: Hoepli.

Pampín, M. F. (2012). Ese don raro de asir la música y el espíritu de las lenguas. Los mecanismos implícitos en el proceso de traducción en la obra de José Martí. Anclajes, 16(2). Recuperado de https://dialnet.unirioja.es/servlet/articulo?codigo=4080617.

Steel, B. (1979). Indicios culturales en el idioma español (Unos apuntes para los estudiantes extranjeros). Yelmo, 27, 16-21.

Trovato, G. (2015). La mediación lingüística y cultural: algunas observaciones acerca de su complejidad conceptual y su colocación en el contexto universitario italiano. Tejuelo, 21, 65-84. Recuperado de https://dialnet.unirioja.es/servlet/articulo?codigo= 5302047.

Trovato, G. (2018). Lingüística española y traducción desde la contrastividad. Roma: Aracne. 
Tejuelo, $n^{\circ} 34$ (2021), págs. 49-82. Comunicar y traducir: una perspectiva cientifica para un enfoque didáctico 